\title{
Isolation, Molecular Cloning and Expression of Human Interferon Gamma (IFN- $\gamma)$ Gene in Escherichia coli
}

\author{
Saber Mohamed Ali ${ }^{1}$, Nadia M. Abdallah ${ }^{2}$, Eman M. Abd El-Azeem ${ }^{2 *}$ and Okasha Hend Ahmed ${ }^{1}$ \\ ${ }^{1}$ Biochemistry Department, Theodor Bilharz Research Institute, Giza, Egypt \\ ${ }^{2}$ Biochemistry Department, Faculty of Science, Ain Shams University, Cairo, Egypt
}

\section{A R T ICLE INFO}

Article history:

Received 17 May 2016

Accepted 26 July 2016

Keywords:

Recombinant human interferon gamma;

Expression;

Cloning;

pET-15b;

Rosetta (DE3);

PBMCS.

\begin{abstract}
A B S T R A C T
Interferon gamma (IFN- $\gamma$ ), also called immune interferon, is chemically and pharmacologically distinct from IFN- $\alpha$ and IFN- $\beta$. It has weaker antiviral activity and more potent immune modulator properties including macrophage activation and is produced mainly by activated T-cells and natural killer. IFN- $\gamma$ is a drug used to reduce the frequency and severity of serious infections associated with chronic granulomatous disease (CGD) and delays the effects of osteopetrosis in patients with severe malignant forms. IFN- $\gamma$ is currently in late stage of clinical trials in treatment of HCV and Leshmaniasis. In the present study hIFN- $\gamma$ was induced and its gene was isolated from human peripheral blood mononuclear cells (PBMC's), analyzed by digestion, sequencing and cloned in pCRII TOPO TA cloning vector to maintain its integrity. The hIFN- $\gamma$ ORF was sub-cloned in pET-15b expression vector and analyzed by PCR. The recombinant pET$15 \mathrm{~b} / \mathrm{hIFN}-\gamma$ vector was transformed into several expression bacterial strains and was successfully expressed using isopropylthio-D-galactoside (IPTG) as an inducer in Rosetta (DE3) bacterial strain and tested by Western blot. The results of this work indicate that the expressed recombinant protein is the hIFN- $\gamma$ protein which was confirmed by the molecular weight and the immunogenicity against the hIFN- $\gamma$ antibodies.
\end{abstract}

\footnotetext{
Introduction

Proteins and peptides are the building blocks of life and are now evolving as a very promising brand of therapeutic entities. Once a rarely used subset of medical treatments, therapeutic proteins have increased dramatically in number and frequency of use since the introduction of first recombinant protein therapeutic viz. human insulin, 25 years ago. Therapeutic proteins and peptides hold a significant role in almost every field of medicine, the demand of recombinant proteins has increased as more applications in several fields become a commercial reality ${ }^{[1]}$.

Interferons (IFNs) were discovered about 50 years ago, as soluble factors produced by chicken cells of the chorio-allantoic membranes after contact with influenza virus, which interfered with subsequent viral infection [2]. They are glycoproteins involved in antiviral, antiproliferative and immunoregulatory processes. The human interferons have been classified into three major types, alpha (leucocytes), beta (fibroblasts) and gamma

* Corresponding author.

E-mail address: emannahas@sci.asu.edu.eg
}

(immune). To variety of different threats, the diversity of IFN provides different immune response ${ }^{[3]}$.

Interferons (IFNs) are an integral part of the immune system, which upon stimulation results in recruitment of cytokines for viral clearance. IFNs have been characterized as potent antiviral agents that can reduce viral titer and have been found to act as critical mediators for tumor regression in few cases. During the course of time Hepatitis $\mathrm{C}$ virus (HCV) has evolved and influence IFN efficiency through various pathways ${ }^{[4]}$.

IFN-y is produced by only two cell types, T-cells and large granular lymphocytes. It is stimulated by mitogen and is involved in the differentiation, maturation, and proliferation of hematopoietic cells. It also enhances nonspecific immunity to tumours, as well as to microbial, viral, and parasitic organisms. Recombinant Human IFN-gamma produced in Escherichia Coli (E. Coli) is a single, non-glycosylated, polypeptide chain containing 144 amino acids and having a molecular mass of 16879 Dalton (17 kDa). Natural human interferon- $y$ (hIFN-y) is composed of 143 amino acid residues. It is glycosylated and does not contain cysteine residues ${ }^{[5]}$. It 
is a homodimer glycoprotein containing approximately 21 to $24 \mathrm{kDa}$ subunits.

The aim of the present study was the isolation, molecular cloning and heterologous expression in E. coli cells of hIFNy gene. This study was also intended to initiate development of strategy for large-scale production of pure human interferon $\mathrm{y}$ proteins for therapeutic purposes in Egypt.

Materials and Methods

In-vitro induction of hIFN- $\gamma$ production in cultured PBMCs

\section{PBMCs separation}

Blood samples were obtained from healthy donors in heparin tubes; PBMC's were isolated from whole blood by centrifugation through Ficoll hypaque ${ }^{\mathrm{TM}}$ plus (Amersham Bioscience Co.) ${ }^{[6]}$.

Concentration of 5x $10{ }^{5}$ PBMCs /ml in RPMI media 1640 containing $10 \%$ fetal calf serum and supplemented with $1 \% \mathrm{~L}$-glutamine, $50 \mu \mathrm{g}$ of gentamycin/ml, $100 \mathrm{U}$ of penicillin $/ \mathrm{ml}$ and $100 \mu \mathrm{g}$ of streptomycin $/ \mathrm{ml}$. The PBMCs were stimulated with phytohemagglutinin (PHA) $(10 \mu \mathrm{g} / \mathrm{ml}){ }^{[7]}$. Suspension was added to 24 well plates and incubated for 24 hours in $\mathrm{CO}_{2}$ incubator. Cells were examined by microscope for viability, and then were harvested for RNA extraction according to single step modified technique ${ }^{[8]}$. RNA agarose gel electrophoresis was utilized to check the intergrity of extracted RNA ${ }^{[9]}$.

\section{Molecular Cloning of hIFN- $\gamma$ into TA cloning vector cDNA synthesis}

In order to obtain the open reading frame (ORF) coding sequence of hIFN- $\gamma$ from mRNA, a pair of oligonucleotide primers were designed using the hIFN- $\gamma$ DNA sequence available in the GenBank database (Accession number, E00598):

- hIFN- $\gamma$ forward primer (With $N c o$ I restriction site) (F1):

\section{5' CACCATGCAGGACCCATATGTAAAA 3}

- hIFN- $\gamma$ reverse primer (With BamHI restriction site) (R1):

\section{AGGATCCTTATTACTGGGATGCTCTTCGA 3`}

The unique $N c o$ I and BamHI restriction sites at the 5' and 3 ' end of amplified hIFN- $\gamma$ were required for subcloning into $\mathrm{pET}-15 \mathrm{~b}$ expression vector.

Reverse transcription polymerase chain reaction (RTPCR) was performed to form cDNA. PCR products were then analyzed by both agarose gel electrophoresis and digestion with restriction enzymes that have been chosen according to the NEB cutter website ${ }^{[10]}$.

Cloning strategy: In order to maintain the integrity of the amplified gene, cloning was done using pCRII TOPO TA cloning vector kit (Invitrogen, USA, Co.) which is designed for seamless cloning of PCR products generated using non-proofreading thermostable DNA polymerases, such as Taq DNA polymerase. This kit provided a highly efficient, 5 min, one-step cloning strategy by using Topoisomerase for the direct insertion of PCR products into a plasmid vector ${ }^{[11]}$.

For optimal results, a $0.5: 1$ molar ratio of PCR product: TOPO vector has been used in the present study.

The ligated material was used for the transformation of E. coli (Top10 strain) (Invitrogen, USA, Co.) according to the standard protocol ${ }^{[12]}$.

The transformation efficiency was calculated from the number of white colonies in the plate as follows:

(cfu on control plate $\times$ dilution factor $\left.\times 10^{3}\right) \div($ ng of control DNA plated)

Transformation efficiency $=150 \times 1 \times 10^{3} \div 0.05 \mathrm{ng}=3$ $\times 10^{6} \mathrm{cfu} / \mu \mathrm{g}$

\section{Blue/white screening of recombinant clones}

The technique is based on vectors such as PCRII TOPO that carry a fragment of the $\beta$-galactosidase gene encoding $\alpha$-fragment of $\beta$-galactosidase. The exploitation of these vectors requires the use of a bacterial strain carrying the complementing gene fragment to allow the assembly of an active complex. Transformation of the vector into appropriate bacteria (Top10) in the presence of substrate (X-gal) results in the formation of blue colonies. Disruption of the $\beta$-galactosidase gene by insertion of a DNA fragment into the vector's multiple cloning site results in the loss of functional $\beta$ galactosidase activity. Therefore, the colonies bearing a vector containing an insert will remain white and may be easily distinguished from those bearing an intact cloning vector $^{[13]}$.

\section{Plasmid DNA preparation}

The white colonies were grown in LB-AMP $(100 \mu \mathrm{g} / \mathrm{ml})$ and plasmid preparation was performed according to the standard protocol ${ }^{[14]}$.

The prepared plasmids were analyzed by PCR protocol, and digestion occurred with $\mathrm{NcoI}$ and BamHI enzymes.

\section{Sequencing}

One of the recombinant clones was sequenced by automated sequencing according to Sanger method ${ }^{[15]}$. Sequencing was done after sample purification by single read service provide by MWG company Munich, Germany, using M13 universal primer. The obtained data were compared with GenBank database using the Blast engine search program ${ }^{[16]}$.

\section{Subcloning of hIFN- $\gamma$ into $p E T-15 b$ vector}

With the intention of subcloning hIFN- $\gamma$ ORF DNA into pET-15b expression vector (Novagen USA, Co.), digestion of pCR II TOPO TA vector carrying the hIFN$\gamma$ gene with $N c o$ I and BamHI restriction enzymes was done. The vector pET-15b was also digested with the same enzymes under similar conditions. The digested products were then purified with a Fermentas DNA extraction kit (Sigma USA, Co.). The 3:1 molar ratio of vector-insert was used for the ligation reaction containing 10x ligase buffer and T4 DNA ligase enzyme (Bethesda Research Laboratories Inc.) and incubated at $16^{\circ} \mathrm{C}$ for $24 \mathrm{hrs}$. The ligated material was used for the transformation of E. coli (Rosetta DE3) (Novagen USA, Co.) according to the standard protocol. 


\section{Expression of hIFN- $\gamma$ in Rosetta DE3}

For protein expression, the bacterial colonies, which contained the recombinant plasmid with hIFN- $\gamma$ gene sequence, were cultured overnight in LB-Amp $(100 \mu \mathrm{g} / \mathrm{ml})$ medium. The culture was then diluted 1:10 $(\mathrm{v} / \mathrm{v})$ in fresh medium and grown for $2 \mathrm{hr}$ at $37^{\circ} \mathrm{C}$ (till $\mathrm{OD}_{600}$ was equal to 0.6) before adding IPTG (Sigma, USA) to $2 \mathrm{mM}$ final concentration. The incubation was continued for further $3 \mathrm{hr}$. The cells were pelleted at $6000 \mathrm{rpm}$ at $4^{\circ} \mathrm{C}$ for 10 minutes, suspended in autoclaved lysis buffer (Tris $\mathrm{HCl} 50 \mathrm{Mm} \mathrm{pH} 7.5$, EDTA $\left.5 \mathrm{Mm}, \mathrm{NaCl} 100 \mathrm{Mm}{ }^{[17]}\right)$. The expressed protein was analyzed by the SDS-PAGE. The Western blotting technique was performed according to sensitive technique ${ }^{[18]}$. The primary antibody rabbit antisera against $\mathrm{hIFN}-\gamma$, and the secondary antibody conjugate goat-anti-rabbit horse raddish peroxidase were used (Komabiotech, Biosource).

\section{Results}

\section{Molecular cloning of hIFN- $\gamma$ cDNA in TA cloning vector}

Total RNA isolated from induced culture of PBMCs was tested for integrity on $1 \%$ formaldehyde- agarose gel. As shown in Figure 1, two bands representing ribosomal RNA: $28 \mathrm{~S}$ and $18 \mathrm{~S}$ were shown on gel, indicating a well preserved integrity of the prepared RNA. RNA has been used for amplification of the hIFN- $\gamma$.

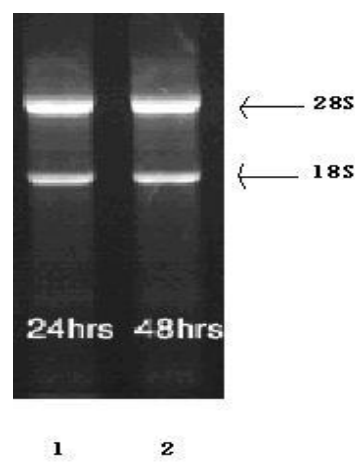

Fig. 1: Agarose gel electrophoresis of total RNA isolated from PBMCs. Lanes $\mathbf{1}$ and $\mathbf{2}$ show RNA extracted from in vitro cultured PBMCs for 24 and 48 hours, respectively.

For PCR experiments, two specific primers were designed according to the available DNA sequence of hIFN- $\gamma$ in GenBank. Figure 2 shows the DNA sequence of the hIFN- $\gamma$ and the position of the F1 (upstream) and R1 (downstream) primers. The designed primers only amplified the coding region of the IFN- $\gamma$ (144 aa) and the leader segment has been excluded.

PCR experiments were carried out using the designed primers and the fractionation of the PCR amplification products on agarose gel electrophoresis showed a sharp band at a molecular size of $\sim 450 \mathrm{bp}$ (Fig. 3).

The confirmation of the amplified fragment (Fig. 4) was done by digestion using Hinf I restriction enzyme. Fractionation of the digestion products on PAGE 10\% has confirmed that the amplified product was digested into two fragments having $\sim 396$ and $\sim 39$ bp as expected from digestion map of hIFN- $\gamma$.

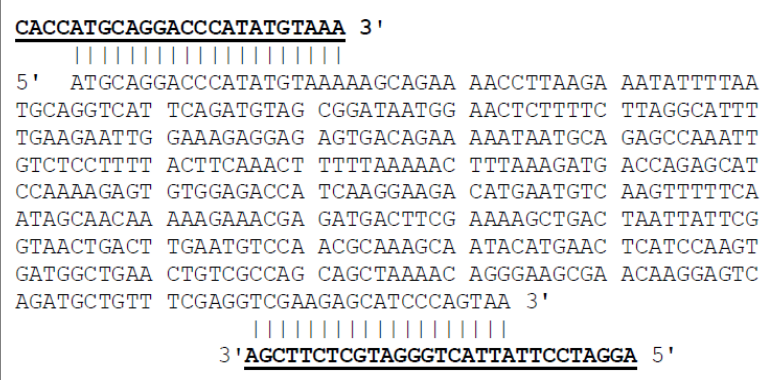

Fig. 2: Alignment between hIFN- $\gamma$ and specific designed primers (F1 and R1). The Block and underlined letters indicate the sequence of primers terminated with the added restriction sequences. The sequence of the ORF of hIFN- $\gamma$ gene started with ATG and ended with TAA, a total of 435 nucleotides (gi: 3458 IFNG).

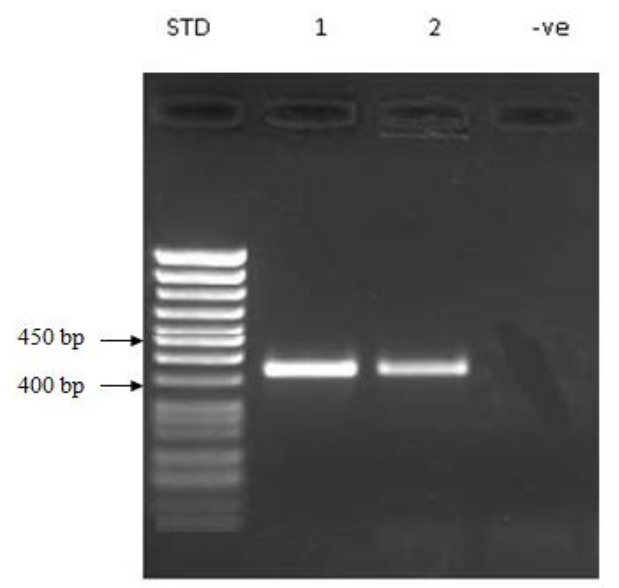

Fig. 3: Agarose gel electrophoresis (3\%) of RT-PCR products of RNA isolated from induced PBMCs culture for 24hrs (lane 1) and for 48hrs (lane 2). STD was $50 \mathrm{bp} \mathrm{DNA}$ ladder (Cornell Lab, Co). The molecular size of the band of RT-PCR product was $\sim 435$ bp. (STD: standard for DNA).

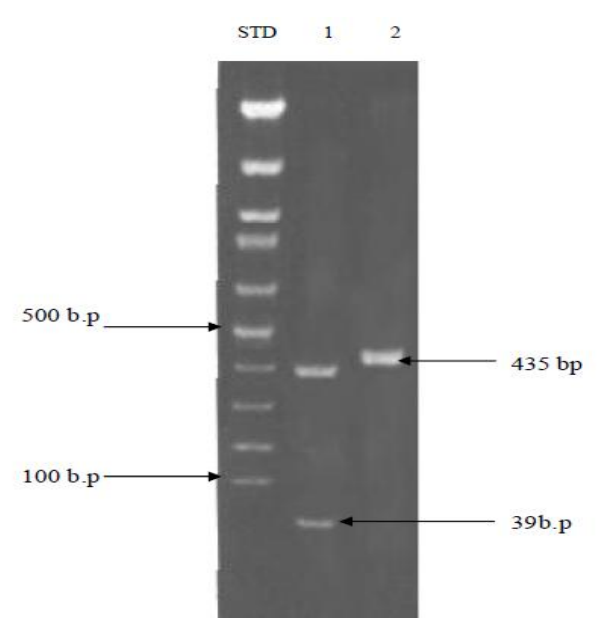

Fig. 4: PAGE (10\%) of the Hinf I digestion fragments of the amplified PCR product. STD: 100 bp DNA ladder (GIBCO BRL, USA). Lane (1): digestion of PCR product showed 2 bands of 396 and 39 bp. Lane (2): undigested RT-PCR amplification products. (STD: standard for DNA). 
The PCR product was ligated into pCRII TOPO TA cloning vector to be transformed into Top 10 chemically competent E. coli cells. A number of the transformed colonies (white colonies) were picked from agar LB plates and lysed by boiling method to prepare plasmid DNA. The DNA was evaluated by electrophoresis on agarose gel.

Isolated plasmids from transformed clones were subjected to PCR using F1 and R1 primers. Amplification resulted in a sharp band at $\sim 435$ bp (the molecular size of hIFN- $\gamma$ ) on agarose gel electrophoresis (Fig. 5).

Digestion of the recombinant plasmids using NcoI and BamHI restriction enzymes was done to ensure the presence of the insert (hIFN- $\gamma$ cDNA). Two bands of $4 \mathrm{~Kb}$ (representing the pCRII TOPO vector) and $435 \mathrm{bp}$ (representing the excised insert) were obtained, indicating that the hIFN- $\gamma$ gene has successfully been cloned into the vector pCRII TOPO (Fig. 6).

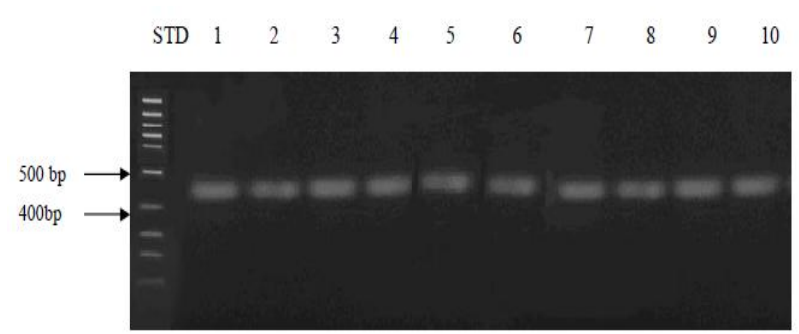

Fig. 5: Electrophoresis on 3\% agarose gel showing PCR amplification product of 10 plasmid preparations using F1 and R1 primers. Lanes 1-10 are PCR product of 10 selected colonies with size 435. STD: 100 bp DNA standard ladder (GIBCO BRL, USA). (STD: standard for DNA).

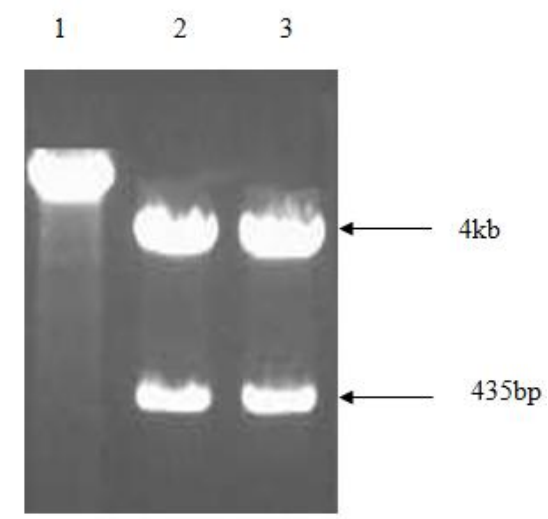

Fig. 6: Electrophoresis on $1.5 \%$ agarose gel shows digested recombinant pCRII TOPO plasmid with $\mathrm{NcoI}$ and BamHI restriction enzymes. Lane 1: undigested recombinant plasmid. Lanes 2 and 3: digestion products show linearized plasmid and insert of $435 \mathrm{bp}(\mathrm{hIFN}-\gamma)$.

\section{Molecular subcloning of hIFN- $\gamma$ cDNA in expression vector}

In order to express the hIFN- $\gamma$ protein, the hIFN- $\gamma$ cDNA was sub-cloned into pET-15b expression vector. Digestion of recombinant pCRII TOPO vector carrying the ORF hIFN- $\gamma$ gene with $N c o$ I and BamHI restriction enzymes was done. The hIFN- $\gamma$ cDNA was excised and eluted from agarose gel; released hIFN- $\gamma$ was ligated to the linearized $\mathrm{pET}-15 \mathrm{~b}$ expression vector digested with the same restriction enzymes ( $\mathrm{NcoI}$ and $\mathrm{BamHI})$. The ligation reaction was followed by transformation into Rosetta DE3 competent cells.

Digestion of the positive clones using restriction enzymes NcoI and BamHI has been performed to ensure the presence of hIFN- $\gamma$ cDNA insert. Two bands of pET$15 \mathrm{~b}$ vector and insert were detected. The insert has the same size of hIFN- $\gamma$ PCR product (Fig. 7).

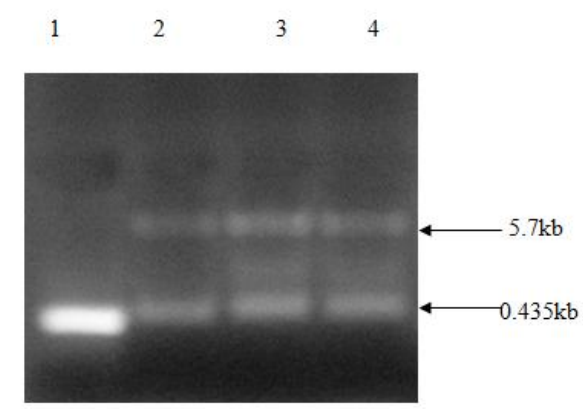

Fig. 7: Agarose gel electrophoresis (1.5\%) shows digestion products of recombinant plasmid with $N c o$ I and BamHI restriction enzymes. Lane 1: hIFN- $\gamma$ PCR product of $435 \mathrm{bp}$. Lanes (2, 3, and 4): two bands of 5.7 and $0.435 \mathrm{~Kb}$ represent the linear pET-15b vector and excised hIFN- $\gamma$ cDNA, respectively.

\section{Recombinant protein expression}

Figure 8 shows that a proper $17 \mathrm{kDa}$ band was obtained with the transformed Rosetta DE3 bacterial cells. The protein was detected in the pellet lysate of Rosetta (DE3) bacteria induced clones. Induction of protein for expression was done by $2 \mathrm{mM}$ IPTG and tested on $15 \%$ SDS-polyacrylamide gel. In contrast, no protein band was found in the non induced bacteria.

Western blot analysis revealed that only one specific band with a molecular weight of $17 \mathrm{kDa}$ was recognized in both; the recombinant protein and the standard hIFN- $\gamma$ (Komabiotech, Biosource), on the membrane (Fig. 9).

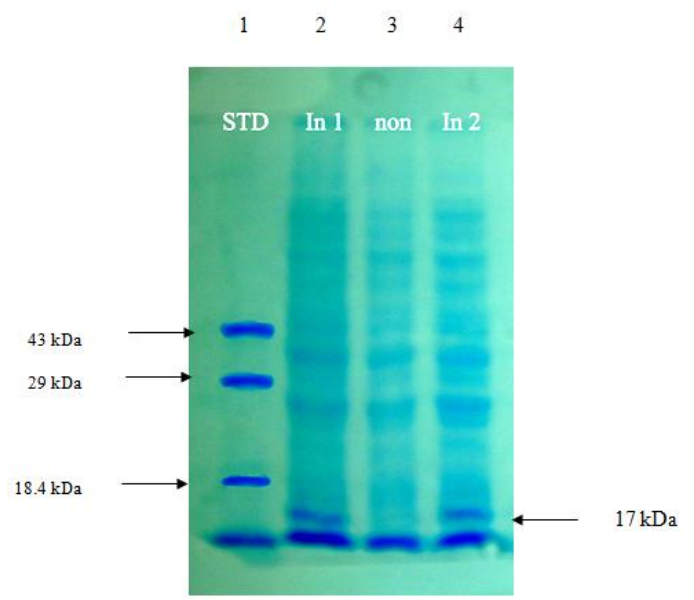

Fig. 8: SDS-PAGE of the lysate of transformed Rosetta (DE3) cells, induced by IPTG. A $17 \mathrm{kDa}$ band is shown in lanes no. 2 and 4; and not detected in the lysate of non induced bacterial cells (lane 3). Lane 1: standard MW proteins. 


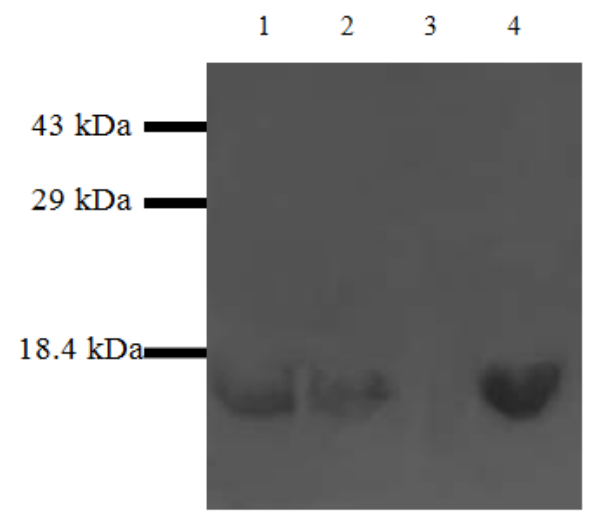

Fig. 9: Western blot analysis of induced recombinant hIFN$\gamma$ in Rosetta (DE3) bacteria, a band was recognized with anti-human IFN- $\gamma$ antibody, Lanes 1 and 2: induced hIFN- $\gamma$ in Rosetta (DE3) bacteria cells, lane 3: the lysate of non induced bacterial cells and Lane 4: recombinant standard hIFN- $\gamma$.

\section{Discussion}

Recombinant DNA technology has now made possible the large-scale production of interferon proteins for pharmaceutical applications. Genes encoding human interferons have been cloned and expressed in recombinant strains of microorganisms and their products have been isolated in a very pure form. $E$. coli has been the most widely used host cells for production of recombinant interferons ${ }^{[19]}$.

Chen et al., ${ }^{[20]}$ investigated the possibility of producing $\mathrm{hIFN} \gamma$ in transgenic rice cell by a sucrose-starvation inducible promoter (rice $\alpha$ Amy 3 promoter). The immunological analysis of the recombinant glycosylated hIFN- $\gamma$ produced was similar to the commercial hIFN- $\gamma$ produced in E. coli.

The goal of the present study was the isolation of total RNA from the induced PBMCs culture to produce hIFN- $\gamma$ cDNA using RT-PCR technique and cloning the hIFN- $\gamma$ ORF in prokaryotic vector for further expression of active recombinant hIFN- $\gamma$ protein in $E$. coli cells.

The first step was the isolation of PBMCs from human blood, using the density gradient centrifugation method. The isolated PBMCs, under sterile conditions have been in vitro stimulated, for induction of hIFN- $\gamma$ mRNA, using mitogen (PHA) that stimulates cell division in lymphocyte cultures. In the same line, Tsujimoto et al., ${ }^{[21]}$ utilized several inducers including PHA and a combined stimulation with OK-432 and SEB to study their synergistic effect on production of hIFN- $\gamma$ protein. In addition, Bandyopadhyay et al., ${ }^{[22]}$ have used different PBMCs inducer, the betel leaf extract alone and in combination with PHA.

In the present study, hIFN- $\gamma$ ORF was amplified by applying RT-PCR technique on the isolated total RNA using two specific designed forward and reverse primers (F1 and R1) which flank the ORF of hIFN- $\gamma$. A series of experimental reactions have been performed with changing the annealing temperature to exclude the nonspecific amplification of other sequences.

Zamani et al., ${ }^{[23]}$ also reported a similar RT-PCR pattern for hIFN- $\gamma$ amplification. Although the annealing temp- erature was higher than that used in the current study, but the MW of PCR products were identical. The difference in annealing temperature was owing to the length of their primers that was longer than the primers in the present work.

Confirmation of the amplified PCR product has been made by using Hinf I restriction enzyme analysis. This enzyme specifically cuts at nucleotide number 396 of hIFN- $\gamma$ and resulted into two fragments of the expected size as predicted by NEB biocutter software digestion map. The result of digestion product was similar to the expected size.

The pCRII TOPO TA cloning vector contains ampicillin resistance marker which permits only transformed bacterial cells to grow in ampicillin containing media. Also it allows blue/white screening of the transformed cell containing the successfully cloned plasmid.

E. coli Top10 host strain was used for transformation as initial cloning step and verification of constructs in the pCRII TOPO TA cloning vectors. The chromosome of Top10 has no T7 RNA polymerase gene; therefore it is ideal for the establishment of recombinant plasmids and not for expression of proteins. With the same strategy, Bagheri et al., ${ }^{[2]}$ have been used the pGEM-TA cloning vector and $E$. coli Top10F host strain for cloning and sequencing of hIFN- $\gamma$ cDNA as initial step for recombinant protein expression in plant cells (Brassica napus seeds). The Top $10 \mathrm{~F}$ E. coli strain overexpresses the Lac repressor (lacIq gene). For blue/white screening, IPTG must be added to the plates to obtain expression from the lac promoter.

The transformation efficiency of chemically competent Top10 cells using the recombinant hIFN- $\gamma$ ORF-pCRII TOPO plasmid was considerably lower than the expected in the kit. Analysis of the white clones has been assured that they contain the constructed hIFN- $\gamma /$ pCRII TOPO recombinant plasmid.

To prove that hIFN- $\gamma$ ORF gene was cloned in the correct orientation, the M13 forward and M13 reverse universal primers were included into the vector to help in DNA sequencing, then the recombinant plasmid (pCRII TOPO/hIFN- $\gamma$ ) was further analyzed by DNA sequencing using M13 universal primers. Sequencing results of 790 nucleotides, representing the complete sequence of the hIFN- $\gamma$ ORF gene and partial sequence of pCRII TOPO vector, has been obtained. Alignment analysis of this sequence (the cloned hIFN- $\gamma$ ORF) showed $100 \%$ homology with reference sequence (Gene ID: 3458 IFNG) retrieved from NCBI GenBank.

The development of $E$. coli cells containing the recombinant plasmid harboring the complete sequence of hIFN- $\gamma$ ORF gene developed by this technology is an achievement in the biotechnology and genetic engineering applied research.

Mariusz., ${ }^{[25]}$ recorded that E. coli lacks the ability to conduct posttranslational modifications; such as glycosylation and disulfide bond formation; whoever, it still provides the optimum choice to produce many pharmaceutical proteins including even complex proteins. 
The amino acid sequence of hIFN- $\gamma$ reveals two potential $\mathrm{N}$ - glycosylation sites at positions 28 and 100; this post-transitional modification has no effect on the in vitro specific activity and the binding of hIFN- $\gamma$ to its cellular receptor and therefore appears to be irrelevant for the protein bioactivity ${ }^{\text {[26-27] }}$.

In the present study several $E$. coli bacterial strains were used for transformation of hIFN- $\gamma / \mathrm{pET}-15 \mathrm{~b}$ recombinant plasmid including: BL21-CodonPlus (DE3)-RIPL, BL21-Gold (DE3) pLysS and Rosetta (DE3), Rosetta 2(DE3) pLYS.

Where hIFN- $\gamma$ protein was expressed under control of promoter T7 in Rosetta (DE3) E. coli strain that is more preferable than the other strains because it is designed to enhance the expression of eukaryotic proteins that contain codons rarely used in E. coli (Arg, Ile, Leu,Gly and Pro) ${ }^{[28]}$.

At the same time, Rosetta-(DE3) is a hybrid strain engineered to enhance the expression of genes and can enhance disulphide bond formation in the cytosolic fraction due to mutations of trxB and gor genes. This strain can yield 10-fold more active protein than other hosts even when overall expression levels are similar ${ }^{[29-30]}$.

In agreement with the current choice, Mehrnoosh et al., ${ }^{[19]}$ declared that Rosetta (DE3) is the most efficient expression system with respect to its high level of protein expression.

Studier and Moffatt, ${ }^{[31]}$ who reported that Rosetta (DE3) is a lysogen of $\lambda$ DE3, and therefore it carries a chromosomal copy of the T7 RNA polymerase gene under control of the lacUV5 promoter, such strain is suitable for production of protein from target genes cloned in pET vectors.

Also the results of this study showed that the conformation of recombinant hIFN- $\gamma$ protein was correctly achieved. These results demonstrated that $E$. coli Rosetta (DE3) would be the choice for production of recombinant hIFN- $\gamma$ protein.

Zamani et al., ${ }^{[32]}$ who demonstrated that hIFN- $\gamma$ protein has been expressed successfully in Chinese Hamster Ovary (CHO) with two potential N-linked glycosylation sites at Asn28 and Asn100 under control of cytomegalovirus (CMV) promoter. Nevertheless, the in vitro post-transitional modification (glycosylation) of recombinant hIFN- $\gamma$ protein has neither effect on specific activity nor binding the cellular receptor.

Also, Babaeipour et al., ${ }^{[28]}$ have produced recombinant hIFN- $\gamma$ protein using high cell density cultivation technique and glucose as carbon source in bench-top bioreactor in order to scale it up into industrial level using the same T7 promoter, pET3a prokaryotic expression vector and 3mM IPTG which was a higher concentration than that used in this study (2mM IPTG), expression was carried out in B121 DE3 E.coli strain.

\section{Conclusion}

In conclusion, results of the present study indicated that recombinant hIFN- $\gamma$ protein was expressed successfully on the lab scale by cloning of hIFN- $\gamma$ ORF gene into
pET-15b expression vector and transformation of Rosetta (DE3) bacterial strain under control of T7 promoter. This will help in production of large amount of this therapeutic protein by scaling up this technology. Further steps of protein purification, isolation and evaluation of its bioactivity are recommended.

\section{References}

1) Muheem, A., Shakeel, F., Jahangir, M. A., Anwar, M., Mallick, N., Jain, G. K., Warsi, M. H. and Ahmad, F. (2016). A review on the strategies for oral delivery of proteins and peptides and their clinical perspectives. Saudi Pharm J., 24(4): 413-428. doi: 10.1016/j.jsps.2014.06.004.

2) Sorgeloos, F., Kreit, M., Hermant, P., Lardinois, C. and Michiels, T. (2013). Review Antiviral Type I and Type III Interferon Responses in the Central Nervous System Viruses, 5: 834-857.

3) Tan, J. S., Ramanan, R. N., Azaman, S. N. A., Ling, T. C. and Shuhaimi, M. (2009). Enhanced interferon- $\alpha 2 \mathrm{~b}$ production in periplasmic space of Escherichia coli through medium optimization using response surface method. Open Biotech. J., 3: $117-$ 124.

4) Akhtar, H., Akhtar, S., Rahee, U., Faheem, M., Arshad, M., Yameen, M. and Zaidi and Najam S. S. (2013). Research Article, Interferons as Immune Regulators: A Rivalry between $\mathrm{HCV}$ and Interferons. J. Clin. Cell Immunol., 4(1).

5) Khalilzadeh, R., Shojaosadati, A., Maghsoudi, E., Mohammadian-Mosaabadi, Mohammadi, M., Bahrami, A., Maleksabet, N., Nassiri-Khalilli Ebrahimi M. and Naderimanesh E. (2004). Process development for production of recombinant human interferon-c expressed in Escherichia coli. J. Ind. Microbiol. Biotechnol., 31: 63-69.

6) Bøyum, A. (1968). Isolation of mononuclear cells and granulocytes from human blood. Scandinavian Journal of Clinical and Laboratory Investigation, 97: 77-89.

7) Katial, R., Sachanandani, D., Pinney, C. and Liberman, M. (1998). Cytokine Production in Cell Culture by Peripheral Blood Mononuclear Cells from Immunocompetent Hosts. Clinical Diagnosis of Laboratory Immunology, 5: 78-81.

8) Chomczynski, P. and Sacchi, N. (1987). Single-step method of RNA isolation by guanidinum thiocyanate-phenol:chloroform extraction. Analytical Biochemistry, 162: 156-159.

9) Farrell, R. (1993). RNA isolation strategies. $2^{\text {nd }}$ edition, Academic Press, San Diego, California. pp: 29-46.

10) Innis, M., Gelfand, D., Sninsky, J. and White, T. (1990). PCR Protocols. A Guide to Methods and Applications. Acadimic Press inc., San Diego, CA, USA. pp: 4-36.

11) Shuman, S. (1994). Novel Approach to Molecular Cloning and Polynucleotide Synthesis Using Vaccinia DNA Topoisomerase. Journal of Biological Chemistry, 269: 32678-32684. 
12) Sambrook, J. and Russell, D. W. (2001). Molecular Cloning. $3^{\text {rd }}$ edition, Cold Spring Harbor Laboratory Press, Cold Spring Harbor, NY, USA. Vol. I, II, III.

13) Sambrook, J., Fritsch, E. and Maniatis, T. (1989). Molecular Cloning: A laboratory manual. $2^{\text {nd }}$ edition, Cold spring Harbor Laboratory Press, NY, USA. Vol. I, II, III.

14) Holmes, D. and Quigley, M. (1981). A rapid boiling method for preparation of bacterial plasmids. Analalytical Biochemistry, 114: 114-121.

15) Sanger, F., Nicklen, S. and Coulson, A. R. (1977). DNA sequencing with chain-terminating inhibitors. Proceedings of the National Academy of Sciences, 74: 5463-5466.

16) Altschul, S. F., Thomas, L. M., Alejandro, A. S., Jinghui, Z., Zheng, Z., Webb, M. and David, J. L. (1997). Gapped BLAST and PSI-BLAST: a new generation of protein database search programs. Nucleic Acids Research, 25: 3389-3402.

17) Smith, D. and Johnson, K. (1988). Single-step purification of polypeptides expressed in Escherichia coli as fusion with glutathione-stransferase. Gene, 67: 31-40.

18) Burnette, W. (1981). Western blotting, electrophoretic transfer of proteins from sodium dodecyle sulfate-polyacrylamide gels to unmodified nitrocellulose and radiographic detection with antibodies and radioiodinated protein A. Analalytical Biochemistry, 112: 195-203.

19) Fathi-Roudsari, M., Akhavian-Tehrani, A. and Maghsoudi, N. (2016). Comparison of Three Escherichia coli Strains in Recombinant Production of Reteplase Avicenna. J. Med. Biotechnol., 8(1): 16-22.

20) Chen, T., Lin, Y., Lee, Y., Yang, N. and Chan, M. (2004). Expression of bioactive human interferon gamma protein in transgenic rice suspension cells. Transgenic Research, 13: 499-510.

21) Tsujimoto, M., Tarutani, T., Ogawa, K., Akashi, K., Okubo, Y. and Higashi, N. (1983). Production of Human Interferon--y in Serum-Free Medium. Infaction and Immunity, 41(1): 181-184.

22) Bandyopadhyay, S., Bharracharyya, S., Roy, M. and Roy, K. (2006). Use of betel leaf extract to induce IFN-gamma production from human peri- pheral blood $\mathrm{T}$ cells and as a Th1 type immunemodulator. US Patent Application Publication. 10: 316-324.

23) Zamani, A., Sadeghian, S., Tavakkol-Afshari, J. and Nasiri, E. (2007). In vitro semi-quantitative determinationof human interferon gamma expression by RT-PCR. Acta Medica Iranica, 45: 7-12.

24) Bagheri, K., Javaran, M., Mahboudi, F., Moeini, A. and Zebarjadi, A. (2010). Expression of human interferon gamma in Brassica napus seeds. African Journal of Biotechnology, 9: 5066-5072.

25) Kamionka, M. (2011). Engineering of Therapeutic Proteins Production in Escherichia coli. Curr. Pharm. Biotechnol., 12(2): 268-274.

26) Arakawa, T., Hsu, Y., Parker, C. and Lai, P. (1986). Human interferon gamma: significance of the C-terminal flexible domain for its biological activity. Journal of Biological Chemistry, 261: 8534-8534.

27) Rinderknecht, E., O'Connor, B. H. and Rodriguez, H. (1984). Natural human interferongamma. Complete amino acid sequence and determination of sites of glycosylation. Journal of Biological Chemistry, 259: 6790-6797.

28) Babaeipour, V., Abbas, S., Rasoul, K., Nader, M. and Mohammad, F. (2010). Enhancement of human gamma-interferon production in recombinant $E$. coli using batch cultivation. Applied Biochemistry and Biotechnology, 160: 2366-2376.

29) Rosano, G. L. and Ceccaelli, E. A. (2014). Recombinant protein expression in Escherichia coli: advances and challenges. Front Microbiol., 5(172): 1- 17.

30) Makino, T., Skretas, G. and Georgiou, G. (2011). Strain engineering for improved expression of recombinant proteins in bacteria. Microb. Cell Fact; 10: 32 .

31) Studier, F. and Moffatt, B. (1986). Use of bacteriophage T7 RNA polymerase to direct selective high-level expression of cloned genes. Journal of Molecular Biology, 189: 113-130.

32) Zamani, A., Tavakkol-Afshari, J. and Alikhan, M. (2006). Molecular Cloning and Expression of Human Gamma Interferon (IFN-g) Full cDNA in Chinese Hamster Ovary (CHO) Cells. Iran Journal of Immunology, 3: 1-8. 